\title{
In memory of Professor Gianni Losano. One year after his death
}

\author{
Daniele Mancardi, Pasquale Pagliaro, Donatella Gattullo, Claudia Penna, Raffaella Rastaldo \\ Department of Clinical and Biological Sciences, University of Turin, Italy
}

Prof. Losano was born on July the 25th 1934, and he graduated in Medicine and Surgery on November 18th 1959. He started his university career in the early 60ties as "Assistente Volontario alla Cattedra di Fisiologia". He was several times a Visiting Professor at the A.M. Dogliotti College of Medicine of the University of Liberia in Monrovia (Liberia), where he also served as Dean of the Medicine Faculty. In 1973 he was named full professor and he continued to work at Torino University until 2019 as Professor Emeritus.

In his early career, his studies focused on haemodynamic, cardiac arrhythmias, and modification of haemodynamic during coronary vessels stenosis. In the early 80 s, professor Losano was famous among students at Torino Medical School, for his studies on cardiovascular physiology with a specific interest in cardiac mechanics. At that time professor Pagliaro was an MD student and was fascinated by the research topics and lifestyle in Professor Losano Lab. Professor Losano and Professor Gattullo managed to involve students in the ongoing studies, and, among them, Professor Pagliaro started to regularly attend the Cardiovascular physiology Lab. In those years, in a collaboration with Professor Neville Marsh from Brisbane, AUT, researches were conducted on the cardiovascular effects of viper (Bitis gabonica) venom. ${ }^{1-3}$

In the same years, within the Physiological Society of London, Professor Losano met Professors David A.S.G. Mary e Ronald Linden, with whom he started collaborating on two main fields of research: a study aimed to understand the role of myogenic response in the regulation of the coronary circle, while the second focused on the mechanisms for the regulation of coronary resistances in presence of coronary partial obstruction. Those studies were published on prestigious Journals, including the Journals of the Physiological Society of London. ${ }^{4-14}$

In 1980, a well-known and cited paper was published by Furchgott and Zawadzki. ${ }^{15}$ This study stimulated excellent

Correspondence: Pasquale Pagliaro, Dept Clinical and Biological Sciences, University of Turin, Italy.

E-mail: pasquale.pagliaro@unito.it

Received for publication: 14 May 2021.

Accepted for publication: 14 May 2021.

${ }^{\text {CC }}$ Copyright: the Author(s), 2021

Licensee PAGEPress, Italy

Journal of Biological Research 2021; $94: 9855$

doi:10.4081/jbr.2021.9855

This article is distributed under the terms of the Creative Commons Attribution Noncommercial License (by-nc 4.0) which permits any noncommercial use, distribution, and reproduction in any medium, provided the original author(s) and source are credited. research leading, in 1986, to the discovery of endothelial-derived nitric oxide from two independent labs. One lab was led by Prof Salvador Moncada, who the University of Torino granted a laurea Honoris Causa in Medicine and Surgery some years later, thanks to Professor Losano support. Professor Losano suggested investigating the role of endothelium and nitric oxide in the regulation of coronary circulation and he involved Professors Neville Marsh, Ronald Linden and Nico Westerhof (Amsterdam) in those studies. Professor Losano's group was among the first to describe the vascular preconditioning. ${ }^{13}$ These studies primed a line of research which lasted for several years and was the topic of several dissertations including the PhD thesis of Pagliaro, Penna and Rastaldo that became collaborators along the way.

Professor Losano loved to participate in person to the experiments and, during those days, there were moments for joking and moments for hard work. He used to pose questions for young fellows, in order to verify the ability to match theory knowledge with practical skills. His aspect was, at first, severe and his voice was peremptory with an atmosphere of fear among newly arrived students. Only the ones who knew him better understood how newcomers could possibly feel under the Professor's questions.

The team building ability of Professor Losano was evident in different ways: he would often gather his group to sit at his old desk in his office to discuss experiments. He was always keen to listen even to the younger participants. The feeling with his collaborators was very important to him, for this reason he used to invite them to his house in the Mentoulle's mountains, where he used to spend time with his numerous and lovely family. After a walk to Fenestrelle fortress, there were always meals with scientific discussions.

Professor Losano was a scientist who dedicated his entire career to promote research in the cardiovascular field, a mentor able to communicate his great passion for research to others. He has always been a promulgator of the importance of basic research as a fundamental starting point to reach over applied research. Professor Losano was appreciated by his own group for his ability to face scientific questions with intelligence. In his long professional career, he demonstrated a great ability to renew his research: he used to challenge himself and his collaborators with new visions and he wouldn't let go until he found appropriate answers; for these reasons he was an example for his collaborators.

His passion for research in the biomedical field and his interest for History, pushed him to avoid the loss of antique and obsolete scientific instruments in the Department of Neuroscience and, with other colleagues, he founded the Historical Scientific and Technological Archive of the University of Torino (ASTUT).

Professor Losano was, for several years, the coordinator of the $\mathrm{PhD}$ programme in Physiology with numerous participants all over Italy. Many of the $\mathrm{PhD}$ students from those years are University Professors today. Moreover, he was one of the founders of the "Consorzio di Ricerche Cardiovascolari" which used to organise, in the beautiful city of Castel Ivano (Trento), important 
scientific meetings as part of the $\mathrm{PhD}$ programme he coordinated. In 1996, after he met Professor Caldarera from the University of Bologna and other scientists, the "Consorzio" merged into the "Consorzio Interuniversitario per la Ricerca Cardiovascolare", which was approved by the deans of 11 Italian Universities. Later, thanks to the work done by the numerous members and to the restless contribution of Professors Losano and Caldarera, the Italian Ministry for University and Research formally approved the request to transform the Consorzio" into the National Institute for Cardiovascular Research". INRC gave several students, and still does, the opportunity to develop an independent research in the cardiovascular field, renovating the attention toward younger scientists always primary in Professor Losano's view.

Almost simultaneously, Professors Losano and Caldarera, along with other professors and researchers gave life to the Italian Society for Cardiovascular Research (SIRC). For several years, the national SIRC meeting was organised in different cities, until when, with the financial support of Fondazione Cassa di Risparmio di Imola (CrImola), it was held in Imola, where it still takes place every two years. Professors Losano and Caldarera, with the sponsorship of Fondazione CrImola, introduced a prize in the name of Antonio Maria Valsalva, notable citizen of Imola. The prize is still attributed to scientists distinguished for their cardiovascular research at international level.

Professor Losano always showed a great respect for young researchers, ready to listen to their fresh ideas. The meeting "New Roads in Cardioscience", now at its 4th edition, was strongly encouraged by Professor Losano to give young researchers a voice. This meeting, organised biannually by SIRC, is, in fact, dedicated to young SIRC members who present and discuss their own works and most valuable receive prizes.

At the beginning of 2000s, thanks to important funding from Compagnia di San Paolo and MIUR (FIRB grant), the study on

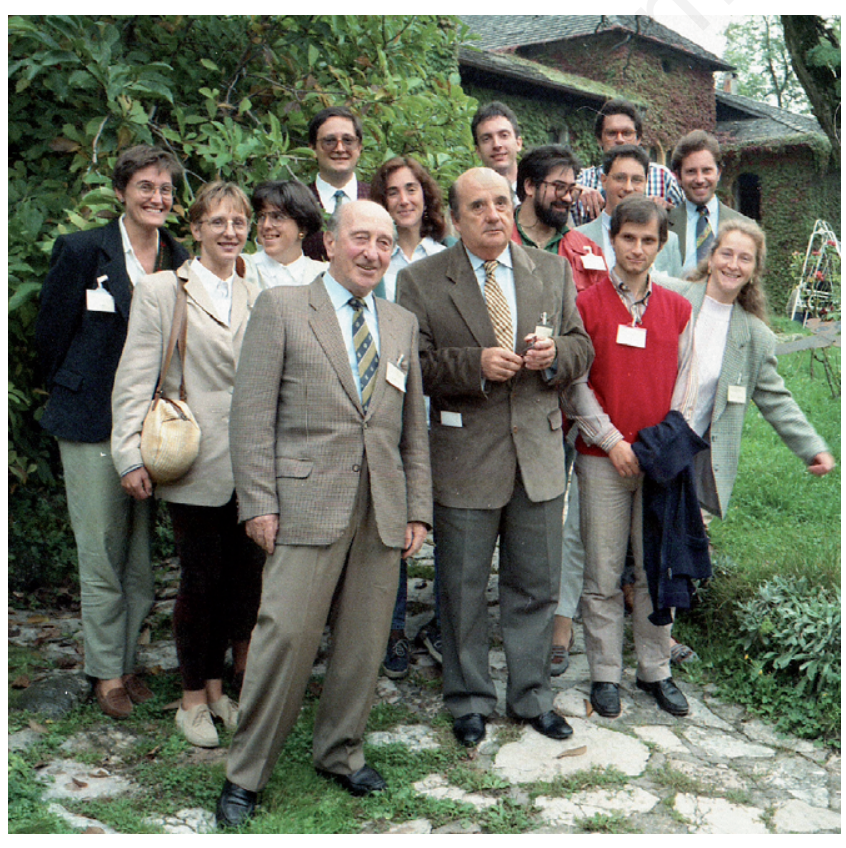

Professors Gianni Losano (right) and Oreste Pinotti (left) together with the students participating in the 1994 Workshop of the Interuniversity PhD Programme in Physiology held in Castel Ivano (TN). stem cells reached Torino. A new line of research started in synergy with other INRC affiliated. In the lab next to where Professor Losano conducted the study on myogenic response and vascular preconditioning, a facility was launched for isolation and characterization of stem cells. The professor dug into this new adventure with the enthusiasm of a younger researcher.

Back in those years, Professor Losano did not abandon his passion for endothelium and endothelial-derived factors. In particular, he began to investigate the role of nitric oxide in myocardial tissue and, later, its role in myocardial protection. This line of research was the most fruitful for his group and it differentiated in different variants, including studies on nitric oxide sibling molecules and other endogenous gaseous molecules involved in the regulation of cardiovascular functions. Among them, hydrogen sulphide and nitroxyl anion have been the subject of several publications from his group components and always attracted the curiosity, attention and support from Professor Losano. ${ }^{16-20}$

Most recently, he fell in love with Apelin. This very interesting molecule, about which he published 5 academic articles. His enthusiasm attracted Professor Rastaldo, at that time a postdoc fellow, who started studying the effect of this endogenous molecule on the cardiovascular system when she was back from the USA. The last scientific work indexed on PubMed from Professor Losano, is indeed a study on the role of Apelin in cardioprotection. This article has been published in 2018 in the prestigious journal Acta Physiologica (Oxford) and it has been introduced by an enthusiastic editorial. ${ }^{21-24}$

Research had a most important role in his life and this passion never faded even after retirement. In fact, he continued to show up at the Department of Neuroscience as Professor Emeritus until his conditions allowed so. He was seeking the scientific discussions also when he was forced home and he would make a daily call to Professor Rastaldo to be updated on new results. He never stopped questioning his collaborators about physiology and he was lately worried about the scarce recruitment at the University.

Professor Losano was co-author of a total of 130 articles on indexed journals with international, to be added to the publication of two textbooks for Medical students and several other books on cardiovascular physiology and the history of medicine. The "Francini-Losano" was a textbook on which several hundreds of students prepared the final exam of human physiology and a lot of physicians still have it in their libraries. In 2014, with Professors Chiribiri, Pagliaro and Rastaldo, he wrote a book on cardiovascular physiology to underline some concepts that did not receive enough attention in other textbooks.

Also his approach to scientific communication was noteworthy: he supported the importance of scientific communication in the international arena and for this reason he advocated the writing of articles in English. He was Editor of the Bollettino della Società Italiana di Biologia Sperimentale. Under his direction this prestigious Italian journal was transformed into the international Journal of Biological Research. His support for scientific dissemination translated into concrete stimuli for young researchers to participate in numerous national and international conferences, contributing with communications and presentations. Even the experiences abroad were highly recommended by Professor Losano and his propensity for confrontation with different realities led some of his collaborators to spend a fruitful period of specialization in the USA. For example, Prof Pagliaro studied the physiological role of pulsatory pressure and coronary endothelium in the regulation of coronary flow in the prestigious research laboratories of Johns Hopkins University in Baltimore. Prof Rastaldo had the opportunity to study stem cells in the field of cardiac regeneration after 
myocardial infarction at the New York Medical College of Valhalla. Dr. Mancardi, at the time PhD student, had the opportunity to perform his research for a couple of years at NIH, Bethesda, where he began to take an interest with Prof. Wink in the physiological role of hydrogen sulphide subsequently applied to cardioprotection.

In his long career he participated in numerous national and international congresses. During the convivial moments of these meetings he liked to report episodes of his life and in particular he loved to remember the experience in Africa, which he had at the beginning of his career. This experience in Africa had marked him very much and he suffered from that form of nostalgia that they call "African sickness". All his pupils and collaborators were "forced" to frequent African or pseudo-African restaurants in Italy and England "jeopardizing their life" as the consequences of his passion for spicy African food. During these trips we also had the opportunity to learn about his passion for art and history. In free moments, the cities were visited and the professor, thanks to his immense culture, transformed himself into a perfect guide.

Prof Losano was attentive towards the needs of the students. He was always available to re-explain concepts to students who had difficulty understanding physiology. Teaching fascinated him, so when he retired gave volunteer lessons to students as he felt that he still had a lot to teach. Until 2018 he was invited by Professor Piergiorgio Montarolo to give lectures on endothelial physiology to the students of Medicine and Surgery of Turin.

Prof Losano was a jovial person and his colleagues certainly remember his strong sense of humor, sometimes a bit biting, and the great self-irony that characterized him.

Prof Losano was a very cultured scientist and those who had the fortune to know him and frequent him have certainly "enriched" their lives. He has always shown particular attention to the personal history of his interlocutor; all of this made him an excellent colleague and friend.

\section{References}

1. Gattullo D, Losano G, Marsh NA, et al. Artificial respiration and survival time in anaesthetized rat after injection of gaboon viper (Bitis gabonica) venom. Boll Soc Ital Biol Sper 1986;62:143-9.

2. Alloatti G, Gattullo D, Losano G, et al. The mechanical effects of rhinoceros horned viper (Bitis nasicornis) venom on the isolated perfused guinea-pig heart. Exp Physiol 1991;76:611-4.

3. Marsh N, Gattullo D, Pagliaro P, Losano G. The Gaboon viper, Bitis gabonica: hemorrhagic, metabolic, cardiovascular and clinical effects of the venom. Life Sci 1997;61:763-9.

4. Gattullo D, Linden RJ, Losano G, et al. The effect of the coronary vascular wall on the changes in the coronary vascular resistance during a sudden reduction and recovery of the aortic blood pressure. Q J Exp Physiol 1986 71:657-74.

5. Dambrosio M, Gattullo D, Linden RJ, et al. Coronary myogenic responses to abrupt changes in aortic blood pressure in anaesthetized dogs. Exp Physiol 1990;75:725-8.

6. Gattullo D, Linden RJ, Losano G, et al. Coronary flow and left ventricular pressure during diastole in the anaesthetized dog. Exp Physiol 1992;77:397-400.
7. Gattullo D, Linden RJ, Losano G, et al. "Resistance" to left ventricular outflow studied in anesthetized dogs. J Med 1993;24:369-83.

8. Gattullo D, Linden RJ, Losano G, et al. Ventricular distension and diastolic coronary blood flow in the anaesthetized dog. Basic Res Cardiol 1993;88:340-9.

9. Gattullo D, Dalla Valle R, Linden RJ, et al. Increases in coronary intravascular pressure during maximal coronary vasodilatation in the anaesthetized dog. Cardiology 1994;84:89-98.

10. Gattullo D, Linden RJ, Losano G, Pagliaro P. Transient effects of quick changes in myocardial metabolism and perfusion pressure on coronary vasomotor responses. Basic Res Cardiol 1994;89:341-53.

11. Gattullo D, Pagliaro P, Linden RJ, et al. The role of nitric oxide in the initiation and in the duration of some vasodilator responses in the coronary circulation. Pflugers Arch 1995;430:96-104.

12. Pagliaro P, Gattullo D, Linden RJ, et al. Systolic coronary flow impediment in the dog: role of ventricular pressure and contractility. Exp Physiol 1998;83:821-31.

13. Gattullo D, Linden RJ, Losano G, et al. Ischaemic preconditioning changes the pattern of coronary reactive hyperaemia in the goat: role of adenosine and nitric oxide. Cardiovasc Res 1999;42:57-64.

14. Di Lavore P, Gattullo D, Guiot C, et al. Effect of tachycardia and constriction of left circumflex artery on coronary flow and pressure in anaesthetized dogs. J Physiol 1988;406:469-81.

15. Furchgott RF, Zawadzki JV. The obligatory role of endothelial cells in the relaxation of arterial smooth muscle by acetylcholine. Nature 1980;288:373-6.

16. Penna C, Rastaldo R, Mancardi D, et al. Effect of endothelins on the cardiovascular system. J Cardiovasc Med (Hagerstown) 2006;7:645-52.

17. Penna C, Rastaldo R, Mancardi D, et al. Post-conditioning induced cardioprotection requires signaling through a redox-sensitive mechanism, mitochondrial ATP-sensitive $\mathrm{K}+$ channel and protein kinase C activation. Basic Res Cardiol 2006;101:180-9.

18. Penna C, Cappello S, Mancardi D, et al. Post-conditioning reduces infarct size in the isolated rat heart: role of coronary flow and pressure and the nitric oxide/cGMP pathway. Basic Res Cardiol 2006;101:168-79.

19. Pagliaro P, Penna C, Rastaldo R, et al. Endothelial cytochrome P450 contributes to the acetylcholine-induced cardiodepression in isolated rat hearts. Acta Physiol Scand 2004;182:11-20.

20. Penna C, Pagliaro P, Rastaldo R, et al. F0F1 ATP synthase activity is differently modulated by coronary reactive hyperemia before and after ischemic preconditioning in the goat. Am J Physiol Heart Circ Physiol 2004;287:H2192-200.

21. Folino A, Accomasso L, Giachino C, et al. Apelin-induced cardioprotection against ischaemia/reperfusion injury: roles of epidermal growth factor and Src. Acta Physiol (Oxf) 2018;222.

22. Losano G, Folino A, Rastaldo R. Role of three adipokines in metabolic syndrome. Pol Arch Med Wewn 2016;126:219-21.

23. Rastaldo R, Cappello S, Folino A, et al. Apelin-13 limits infarct size and improves cardiac postischemic mechanical recovery only if given after ischemia. Am J Physiol Heart Circ Physiol. 2011;300:H2308-15.

24. Lionetti V. Cardioprotection gain with apelin-13: A matter of signalling. Acta Physiol (Oxf) 2018;222. 